\title{
REDisTRIBUTION OF STOCK SECTIONS ACCORDing TO THE MATERIALS TURNOVER AND THE ABC METHOD
}

\author{
Milan Jemelka, Bronislav Chramcov \& Pavel Kříž
}
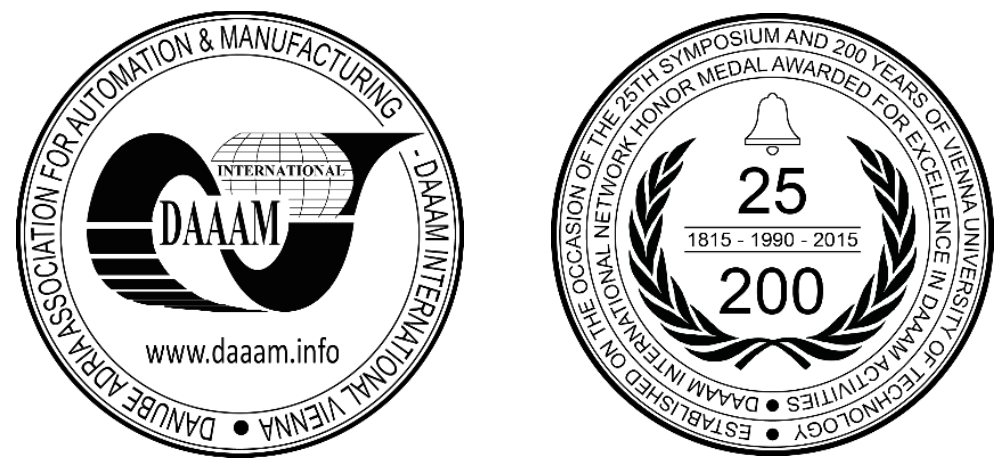

This Publication has to be referred as: Jemelka, M[ilan]; Chramcov, B[ronislav] \& Kriz, P[avel] (2016). Redistribution of Stock Sections According to the Materials Turnover and the ABC Method, Proceedings of the 27th DAAAM International Symposium, pp.0816-0821, B. Katalinic (Ed.), Published by DAAAM International, ISBN 978-3-90273408-2, ISSN 1726-9679, Vienna, Austria

DOI: $10.2507 / 27$ th.daaam.proceedings. 118

\begin{abstract}
The paper focuses on redistribution of stock sections and shortening forklift handling distances. By analysing the stock according to the turnover of the raw materials and redistributing the storage sections according to the ABC method based on the turnover leads to shortening tracks of forklifts. Moreover, a comparison of the original 12 section layout based on practical experience of warehouse operators is also added to the article and compared with the computed solution according to the turnover of the raw materials based on the $\mathrm{ABC}$ method.
\end{abstract}

Keywords: ABC classification; ABC analysis; putaway strategy; inventory planning.

\section{Introduction}

$\mathrm{ABC}$ analysis is a well-established categorization technique based on the Pareto Principle for determining which items should get priority in the management of a company's inventory. In discussing this topic, today's operations management and supply chain textbooks focus on dollar volume as the sole criterion for performing the categorization. The authors argue that today's businesses and supply chains operate in a World where the ability to deliver the right products rapidly to very specific markets is key to survival. With suppliers, intermediaries, and customers all over the globe, and products live decreasing rapidly, this focus on a single criterion. The large body of research was summarized based on multiple criteria ABC analysis that has accumulated since the 1980s and recommend that textbooks incorporate their key findings and methods into their discussions of this topic. Suggestions are offered on how this discussion might be structured.

Inventory control was a well-known problem in operations research. A large number of authors solved this issue [1, 2, 3, 21, 22] and several models have been developed to solve inventory problems [23]. Business companies have hundreds of different types of materials. Therefore, it is easy to lose control of managing the materials. Inventory classification using $\mathrm{ABC}$ analysis is one of the most widely used techniques in organizations. ABC classification allows an organization to separate stock keeping units (SKU) into three groups: A, the most important; B, important; and C, the least important. Most management efforts and oversights are expended on managing $\mathrm{A}$ items. $\mathrm{C}$ items get the least attention and B items are in-between. The purpose of classifying items into groups is to establish appropriate levels of control over each item $[4,5,6]$. The major advantage of $\mathrm{ABC}$ analysis is the easiness of use and simplicity to understand. 
The items are classified according to the annual use value, which is the product of annual demand and the average unit price $[7,8]$. The classification of items into A, B, and C groups has generally been implemented according to one criterion.

For inventory items, the criterion is frequently the annual dollar usage of the item. However, it has been generally recognized that the traditional $\mathrm{ABC}$ analysis has a serious drawback that may inhibit the effectiveness of the procedure in some situations. Using one criterion only may create problems of significant financial loss. For example, class $\mathrm{C}$ items with long lead time or class A items prone to obsolescence may incur financial losses due to a possible interruption of production or huge inventory levels. $[9,10,11]$ Therefore, it has been proposed that multi-criteria ABC classification, such as lead time, criticality of a stock out of the item, the rate of obsolescence, the scarcity, substitutability, and order size requirement of the item, can provide a more comprehensive managerial control and to take other important criteria into consideration $[12,13,14]$.

In this paper, we are concerned with the $\mathrm{ABC}$ classification method aimed to facilitate inventory management and to divide the inventory material into new sections $[15,16,17]$. This classification method will affect the distribution of the materials and we will perform efficiency measurement $[18,19,20]$.

\section{Problem formulation}

An inefficient layout of a warehouse can have a negative effect on business performance. The two main variables on which every warehouse's performance is based are the space required for allocation of items and the time needed for their handling [8]: space and time are obviously related to the selected storage policy. Without any loss of generality, it is possible to say that permanently assigning certain slots to each SKU ensures a notable ease in tracing items locations. This procedure, combined with the opportunity of properly placing fast/slow mover products in specific warehouse areas also enables a reduction of material handling times [9].

The original warehouse is divided into 12 sections and put away of raw materials into individual sections is carried out intuitively, based on the past experience of forklift operators. The aim is to enhance all the stock operation based on the $\mathrm{ABC}$ analysis [12]. The observed variable is the total distance of the warehouse forklift operations.

\subsection{Description of current storage location}

The storage hall has a total size of 23,520 square meters. The length of the hall is 210 meters and the width is 56 meters. This storage hall is designed for storage of raw materials. All the inbound deliveries and the outbound deliveries are processed in one point. All operations are performed by forklifts. Shelves are used for each of these sections. SKUs are stored in bins. Bin is a special location of a shelve to store multiple SKUs at one place.

The materials are originally placed randomly in these shelves, which are divided in 12 sections (see Fig.1a). These sections were designed by warehouse operators based on their experience. All operations are managed by forklifts and operation of this storage area is continual. 1063 types of raw materials are being stored in warehouse. The warehouse capacity comprises 71442 storage positions (Bins). Maximum capacity and number of stored raw materials types are displayed down here in the Table 1.

\begin{tabular}{|c|r|r|}
\hline Sections & Maximum number of bins & Number of material types \\
\hline A01 & 2912 & 81 \\
\hline A02 & 75 & 10 \\
\hline A03 & 11474 & 141 \\
\hline A04 & 6004 & 77 \\
\hline A05 & 7543 & 98 \\
\hline A06 & 2785 & 37 \\
\hline A07 & 9881 & 99 \\
\hline A08 & 8462 & 113 \\
\hline A09 & 4429 & 61 \\
\hline A10 & 7958 & 100 \\
\hline A11 & 3580 & 51 \\
\hline A12 & 6339 & 195 \\
\hline SUM & $\mathbf{7 1 4 4 2}$ & $\mathbf{1 0 6 3}$ \\
\hline
\end{tabular}

Table 1. The existing structure and capacity of the warehouse 
a)

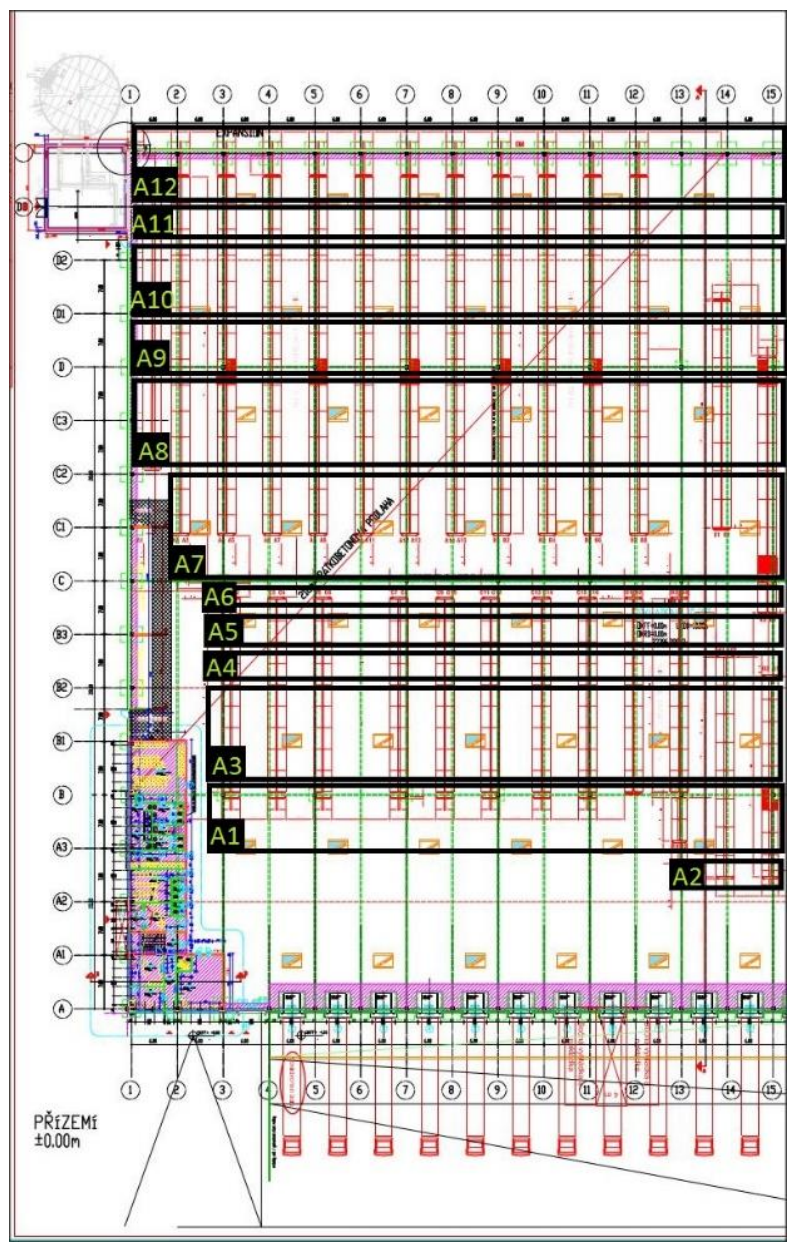

b)

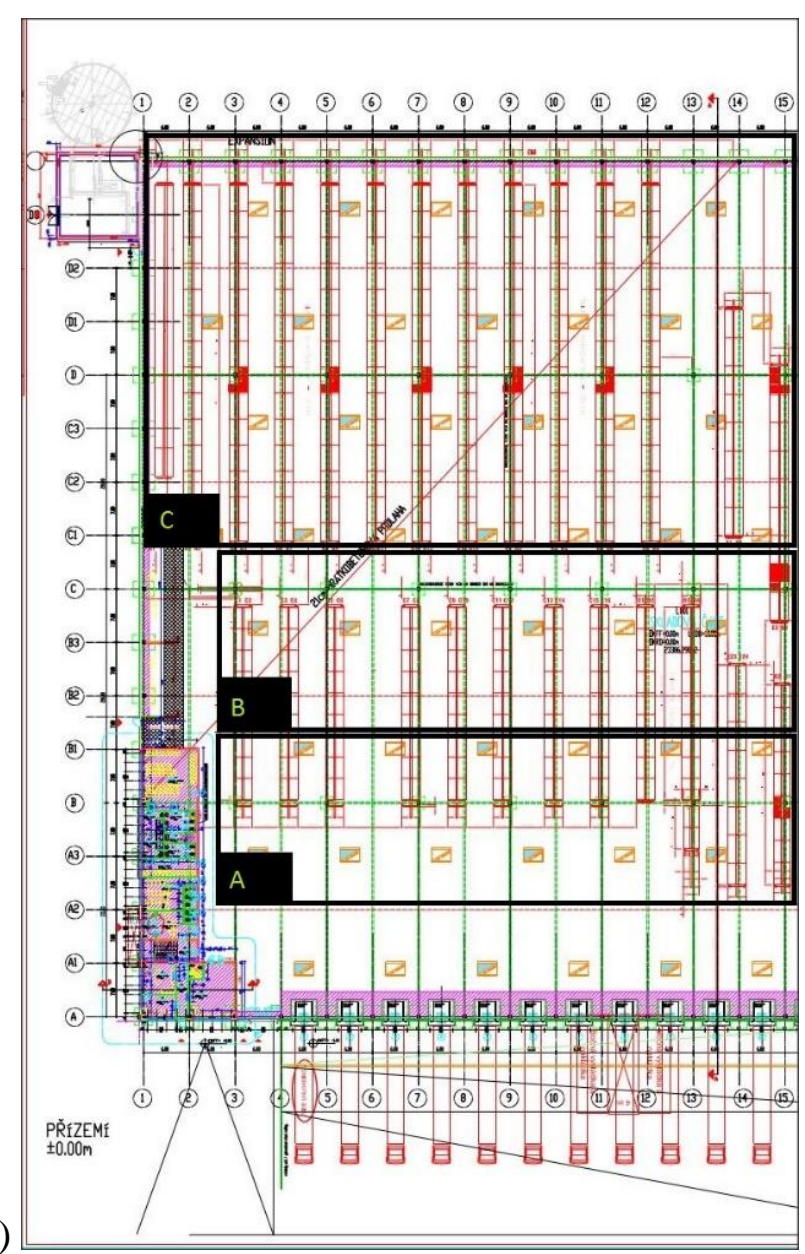

Fig. 1. Warehouse layout (a-current state, b-new design)

\section{New warehouse layout}

The new warehouse layout is based on the $\mathrm{ABC}$ analysis. Based on this analysis, the storage hall is divided into three managed areas (see Fig. 1b). The largest storage section is the area A, smaller section is the area B and the smallest section is the area C. Ratio 4:2:1 is determined for the individual sections allocation.

All the raw materials are divided into three types A, B, C (Pareto principle) according to their turnover. The A raw material is used the most frequently. Their turnover rate is less than one day. The consumption of these raw materials comprises approximately $80 \%$ of the total consumption of raw materials. The B raw materials have turnover less than one week. The consumption of these raw materials comprises approximately $15 \%$ of the total consumption. The $\mathrm{C}$ raw materials have turnover greater than one week. According to this classification, raw materials are put-away into individual sections of $\mathrm{A}, \mathrm{B}$, or $\mathrm{C}$.

\section{$4 \quad$ Analysis and results}

\subsection{Analysis of the current state}

During the design and analysis phases were used real data obtained from the information system of the warehouse. Period of 90 days was observed. Data of this period was analysed and A, B, and C groups were determined based on the turnover information. The values are clearly presented in Table 2.

\begin{tabular}{|l|c|c|c|}
\hline & A & B & C \\
\hline Total number of raw material types & 142 & 249 & 672 \\
\hline Turnover for 90 days & 135 & 14 & 1.8 \\
\hline
\end{tabular}

Table 2. The average turnover of each raw material type 
Analysis of the current 12 sections state is outlined in details in Table 3 . The table presents the distribution of each raw material type in sections 1 to 12 . It is evident that the division into individual sections does not consider the raw materials turnover. Distribution is intuitive, more or less random. These sections were designed by warehouse workers based on their own experience. Furthermore, the table indicates the number of units that were withdrawn in the period of 90 days in all the sections and the distance needed to dispatch all these SKUs.

\begin{tabular}{|c|c|c|c|c|c|}
\hline Sections & A & B & C & $\begin{array}{l}\text { The number of } \\
\text { SKUs in 90 days }\end{array}$ & $\begin{array}{l}\text { The track of a } \\
\text { forklift (km) }\end{array}$ \\
\hline A01 & 26 & 9 & 46 & 3719 & 31.83 \\
\hline A02 & 3 & 1 & 6 & 430 & 7.45 \\
\hline A03 & 13 & 40 & 88 & 2473 & 126.85 \\
\hline A04 & 19 & 13 & 45 & 2828 & 290.33 \\
\hline A05 & 14 & 24 & 60 & 2334 & 332.56 \\
\hline A06 & 9 & 9 & 19 & 1375 & 237.69 \\
\hline A07 & 15 & 26 & 58 & 2493 & 523.80 \\
\hline A08 & 4 & 27 & 82 & 1066 & 281.31 \\
\hline A09 & 6 & 9 & 46 & 2581 & 307.56 \\
\hline A10 & 15 & 33 & 52 & 1824 & 873.00 \\
\hline A11 & 12 & 11 & 28 & 1724 & 679.06 \\
\hline A12 & 6 & 47 & 142 & $\mathbf{2 3 8 6 6}$ & 691.80 \\
\hline SUM & $\mathbf{1 4 2}$ & $\mathbf{2 4 9}$ & $\mathbf{6 7 2}$ & $\mathbf{4 3 8 3 . 2 5}$ \\
\hline
\end{tabular}

Table 3. Results of the current state analysis

\subsection{Results for ABC classification}

All the ABC analysis results are clearly presented in Table 4. It is apparent from the table, that approximately $80 \%$ of SKUs, which are transported, are included in sector A. Contrary the least transported raw materials are located in sector C. The average length of the tracks in each section was used for calculating the overall track of forklifts. These lengths are also recorded in Table 4.

\begin{tabular}{|l|c|c|c|c|}
\hline & A & B & C & SUM \\
\hline The number of raw material types & 142 & 249 & 672 & 1063 \\
\hline Turnover of one material type for 90 days (estimate) & 135 & 14 & 1.8 & \\
\hline The number of SKUs in 90 days & 19170 & 3486 & 1210 & 23866 \\
\hline Average forklift track into each section and back [m] & 120 & 300 & 390 & \\
\hline The total track of forklift $[\mathbf{k m}]$ & 2300.4 & 1045.8 & 471.744 & $\mathbf{3 8 1 7 . 9 4 4}$ \\
\hline
\end{tabular}

Table 4. Results for the ABC analysis

\subsection{Overall conclusion}

Benefit of the ABC method is obvious from the evident Table 5. One line was completed with the results of the random manipulation of raw materials for interest reasons.

The average total length of forklift truck route is $160 \mathrm{~m}$ and this length includes both routes in one operation. Due to rearrangement of the warehouse area, the total route distance of the forklift decreased by $12.9 \%$ that means $565.3 \mathrm{~km}$.

The $12.9 \%$ saving of the route distance enables the company to reduce staff, saving labour costs every month. Moreover, this new finding will have a positive impact on reducing the amount of labour intensity of forklift operators and will have positive effect on a greater well-being at work and to society by reducing the total distance. 


\begin{tabular}{|l|c|c|}
\hline & The total track of forklift & $\begin{array}{c}\text { The average forklift length during } \\
\text { manipulation of one SKU }\end{array}$ \\
\hline The current status of the 12 sectors & $4383.25 \mathrm{~km}$ & $183.7 \mathrm{~m}$ \\
\hline ABC analysis & $3817.94 \mathrm{~km}$ & $160 \mathrm{~m}$ \\
\hline Random stock (12 sections) & $5011.86 \mathrm{~km}$ & $210 \mathrm{~m}$ \\
\hline
\end{tabular}

Table 5. Comparison of the results

\section{Conclusion}

Traditionally, $\mathrm{ABC}$ analysis has been used to classify various inventory items into three categories - A, B, and C. The design of a warehouse, ensuring its optimum layout configuration and effective material handling system, is strictly related to an accurate and structured allocation of products according to the $\mathrm{ABC}$ method. The main aim of the proposed formulation was to enhance the necessary storage space while determining a proper $\mathrm{ABC}$ material allocation to reduce handling times and distances. The proof is a real industrial case, showed the effectiveness of the formulation, depicting performances notably close to the best feasible case. Though using a dedicated storage policy approach, the outcomes obtained through the developed formulation resulted in being equal to the lower bound computed using a randomized policy which, distinct from the presented technique, should be unavoidably sustained by warehouse management system software. Thus, the proposed approach allows companies of all sizes to optimize their warehouse, reducing the required storage space to a minimum while adopting the ABC method within their ERP system.

The problem was to verify, if the current storage location is distributed correctly. Our calculation confirmed, that ABC analysis delivers the effective warehouse layout and saved $13 \%$ of forklift manipulation movements. The positive outcome is, that this method is fast and most of the world enterprise resource planning software can generate the $\mathrm{ABC}$ analysis by themselves based on various criteria.

This is a real industrial case, which can be implemented in any warehouse location.

The future plans are to use different $\mathrm{ABC}$ ratios to distribute the warehouse area and to find the most effective one.

\section{Acknowledgments}

This work was supported by the Ministry of Education, Youth and Sports of the Czech Republic within the National Sustainability Programme project No. LO1303 (MSMT-7778/2014) and also by the European Regional Development Fund under the project CEBIA-Tech No. CZ.1.05/2.1.00/03.0089 and also by the Internal Grant Agency of Tomas Bata University under the project No. IGA/FAI(CEBIA)/2016/033.

\section{References}

[1] Cecil-Wright, J. (1986). How the boardroom can influence warehousing costs. International Journal of Retail \& Distribution Management, 14 (3), 67-69.

[2] Segerstedt, A., Pettersson, A.I. (2012). Measurements of excellence in a supply chain. International Journal of Logistics Systems and Management, 13 (1), 65-80.

[3] Hausman, W.H., Schwarz, L.B. and Graves, S.C. (1976). Optimal storage assignment in automatic warehousing system. Management Science, 22 (6), 629-638.

[4] Muppani, V.R., Adil, G.K. and Bandyopadhyay, A. (2010). A review of methodologies for class-based storage location assignment in a warehouse. International Journal of Advanced Operations Management, 2 (3-4), 274-291.

[5] Kovacs, A. (2011). Optimizing the Storage Assignment in a Warehouse Served by Milkrun Logistics. International Journal of Production Economics, 133 (1), 312-318.

[6] Glock, C.H. and Grosse, E.H. (2012). Storage policies and order picking strategies in U-shaped order picking systems with a movable base. International Journal of Production Research, 50 (16), 4344-4357.

[7] De Koster, R.B.M., Le-Duc, T. and Zaerpour, N. (2012). Determining the number of zones in a pick and-sort order picking system. International Journal of Production Research, 50 (3), 757-771.

[8] Bragg S. M. (2013) Inventory Management, Accounting Tools, Colorado.

[9] Waters D. (2003) Inventory Control and Management (Business), John Wiley and Sons, 2nd edition.

[10] Piasecki D. J. (2009)., Inventory Management Explained, Ops Publishing.

[11] Granville D. (2007). Excellence in Inventory Management: How to Minimise Costs and Maximise Services, Cambridge Academic; First edition.

[12] Milner C. (2015). Inventory Management: Advanced Methods for Managing Inventory within Business Systems, Kogan Page; 1 edition. 
[13] Grinsted S. (2013). The Logistics and Supply Chain Toolkit: Over 90 Tools for Transport, Warehousing and Inventory Management, Kogan Page; 1 edition.

[14] Muller M. (2011). Essentials of Inventory Management, Amacom, 2nd edition.

[15] Bottani E., R. Montanari, M. Rinaldi and G. Vignali (2015). Intelligent algorithms for warehouse management. Intelligent Systems Reference Library, 87, pp. 645-667.

[16] López J. A, Mendoza A. and J. Masini (2013). A classic and effective approach to inventory management. International Journal of Industrial Engineering: Theory Applications and Practice, 20 (56), pp. 372-386.

[17] Xiao Y., Zhang R. and I. Kaku (2011). A new approach of inventory classification based on loss profit. Expert Systems with Applications, 38 (8), pp. 9382-9391.

[18] Paweł P., Marek F. and G. Paulina (2008). Using ABC Classification to determine production sequence in automotive industry, In Proceedings of 2008 World Automation Congress, WAC 2008, IEEE, pp. 1-6.

[19] Smith A.D. (2011). Inventory management and ABC analysis practices in competitive environments. International Journal of Procurement Management, 4 (4), pp. 433-454.

[20] Miculescu, M. N.; Lut, D. M. \& Miculescu, C. (2011). Current Trends of Production Cost Accounting, Annals of DAAAM for 2011 \& Proceedings of the 22nd International DAAAM Symposium, 23-26th November 2011, Vienna, Austria, Volume 22, No. 1, ISSN 1726-9679, ISBN 978-3-901509-83-4, Katalinic, B. (Ed.), pp. 0941-0942, Published by DAAAM International Vienna, Vienna

[21] Pasic, M.; Kadric, E. R. \& Bajric, H. (2010). Relationship between Inventory Investment and Forecasting and Inventory Control, Annals of DAAAM for 2010 \& Proceedings of the 21st International DAAAM Symposium, 2023rd October 2010, Zadar, Croatia, ISSN 1726-9679, ISBN 978-3-901509-73-5, Katalinic, B. (Ed.), pp. 0511-0512, Published by DAAAM International Vienna, Vienna

[22] Knezevic, B. (2011). Usage of Simulation in Inventory Management Education, Annals of DAAAM for 2011 \& Proceedings of the 22nd International DAAAM Symposium, 23-26th November 2011, Vienna, Austria, Volume 22, No. 1, ISSN 1726-9679, ISBN 978-3-901509-83-4, Katalinic, B. (Ed.), pp. 1197-1198, Published by DAAAM International Vienna, Vienna

[23] Gastermann, B. C.; Luftensteiner, F.; Stopper, M. \& Katalinic, B.: Multiple Stage Production Planning in Plain Manufacturing Environments, Annals of DAAAM for 2012 \& Proceedings of the 23rd International DAAAM Symposium, ISBN 978-3-901509-91-9, ISSN 2304-1382, pp 0883 - 0886, Editor B[ranko] Katalinic, Published by DAAAM International, Vienna, Austria, 2012 